\title{
Archéopages
}

Archéopages

Archéologie et société

\section{Dépôt de truies en silos et fossés dans des sites gaulois de Beauce}

\section{Grégory Bayle et David Josset}

\section{(2) OpenEdition}

1 Journals

Édition électronique

URL : https://journals.openedition.org/archeopages/291

DOI : 10.4000/archeopages.291

ISSN : 2269-9872

\section{Éditeur}

INRAP - Institut national de recherches archéologiques préventives

\section{Édition imprimée}

Date de publication : 1 mai 2013

Pagination : $32-33$

ISSN : $1622-8545$

\section{Référence électronique}

Grégory Bayle et David Josset, " Dépôt de truies en silos et fossés dans des sites gaulois de Beauce », Archéopages [En ligne], 35 | 10/2012, mis en ligne le 01 octobre 2014, consulté le 22 janvier 2022. URL : http://journals.openedition.org/archeopages/291; DOI : https://doi.org/10.4000/archeopages. 291 

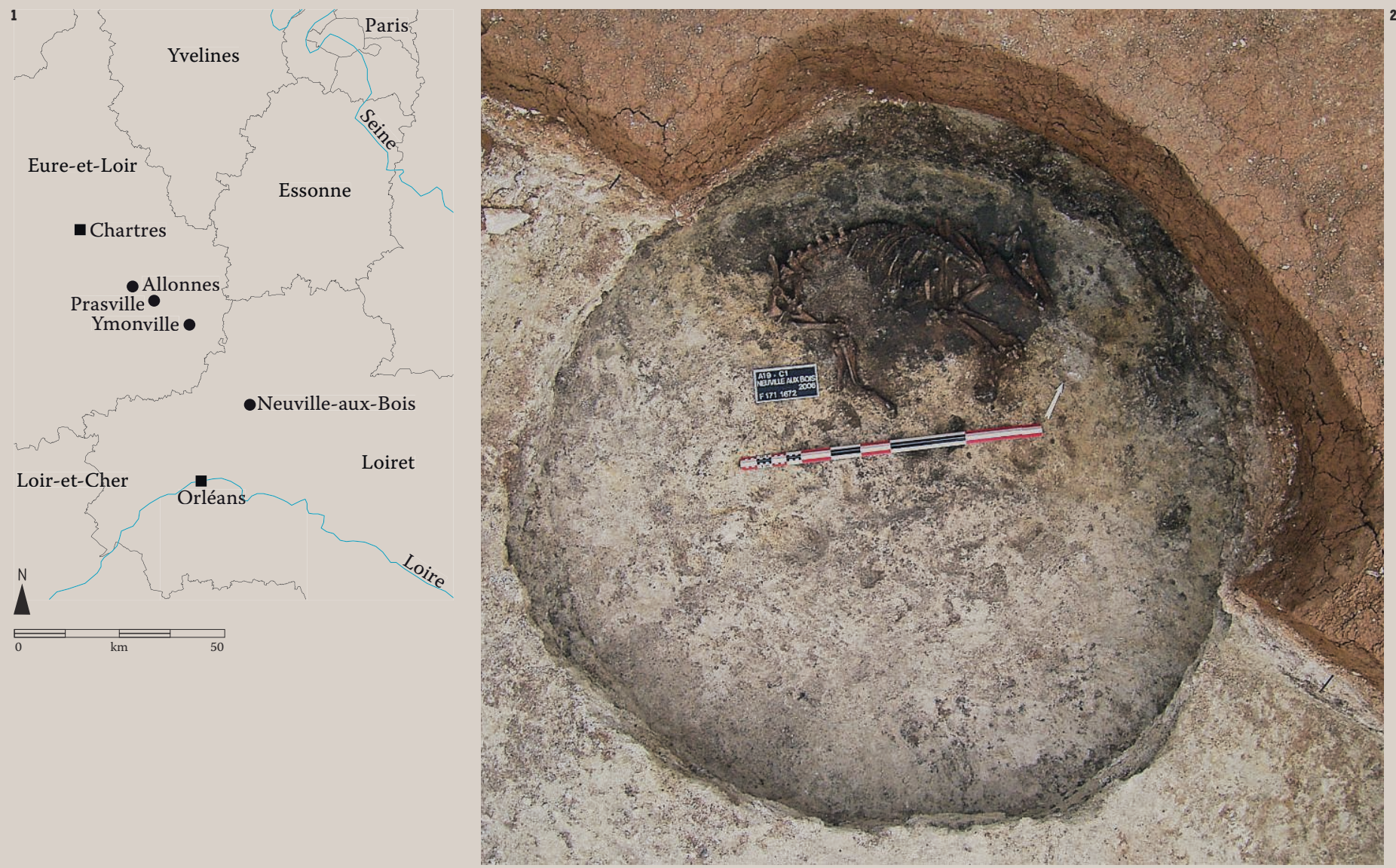

\title{
Dépôt de truies
} en silos et fossés dans des sites gaulois de Beauce

\author{
Grégory Bayle Irrap, UMR 7324 CITERES \\ David Josset Inrap, UMR 8546 AOROC
}

Le porc (Sus scrofa domesticus) à la période de La Tène est connu principalement par ses restes osseux issus de dépotoirs domestiques. Même s'il a pu servir d'éboueur, sa fonction première a toujours été de fournir de la viande et d'autres produits dérivés (graisse, tendons...). C'est particulièrement manifeste dans les sociétés du nord de la Gaule où il tient une place importante dans l'alimentation carnée sur de nombreux sites découverts (Méniel, 2001). Si la gestion de ces troupeaux porcins peut être appréhendée par les âges d'abattage et le sex-ratio (Horard-Herbin, 1997), leurs conditions de vie et leurs rapports quotidiens avec ces sociétés sont peu renseignés. L'hypothèse communément admise est celle de populations vivant en semiliberté dans l'environnement proche des habitations (Méniel, 2005). Flle peut être soutenue par les découvertes occasionnelles de squelettes de périnataux dans des structures en creux à proximité des lieux de vie (fossés, silos, fosses). Rares sont, en revanche, les squelettes d'individus plus âgés découverts dans ces mêmes contextes, car ces sujets sont aussi couramment abattus que les plus jeunes à des fins alimentaires.

Ces dernières années, quatre sites datés de la Tène, dans un secteur relativement restreint (environ $50 \mathrm{~km}^{2}$ ), entre Chartres et Orléans, ont livré des squelettes entiers de vieille truie [ill. 1]. À Neuville-aux-Bois « la Grande Route »
(Loiret), il s'agit

d'un squelette d'une vieille truie couchée sur son flanc gauche [ill. 2], au fond de l'un des silos datés de La Tène B1/BZ (Josset, 2009), rapidement recouvert de déchets culinaires. Autre cas similaire à Prasville « Les Grandes Canettes » (Eure-et-Loir), où un squelette de truie âgée, couchée sur le flanc droit, a été découvert dans les comblements intermédiaires d'un des silos, daté cette fois-ci de La Tène BZ/C1 (Lusson, 2011). Dans les comblements intermédiaires du fossé d'enclos du site d'Allonnes « l'Ouche du Pigeonnier» (Fure-et-Loir), daté de La Tène $C$, a été trouvé un squelette de truie âgée de plus de sept ans, ainsi qu'un squelette de porcelet périnatal (Bailleux, Vacassi, 2011). Enfin, ce sont trois squelettes plus ou moins complets de truies âgées ${ }^{1}$ [ill. 3], retrouvés séparément dans des fossés sur le site d'Ymonville « Les Hyèbles » (Fureet-Loir), large regroupement d'habitats occupés dès le Hallstatt final et pendant toute La Tène, mais avec une intensité plus importante au cours de la Tène $B$ et $C$.

Ces six truies présentent la caractéristique d'être relativement âgées, mortes probablement naturellement, de ne pas avoir été découpées et d'avoir été rapidement recouvertes de déchets. Sur ces six cas, deux ont été trouvés dans des aires d'ensilages où des structures d'habitations n'ont pas été mises en évidence (Neuville-aux-Bois et Prasville). Dans le cas d'Ymonville, 


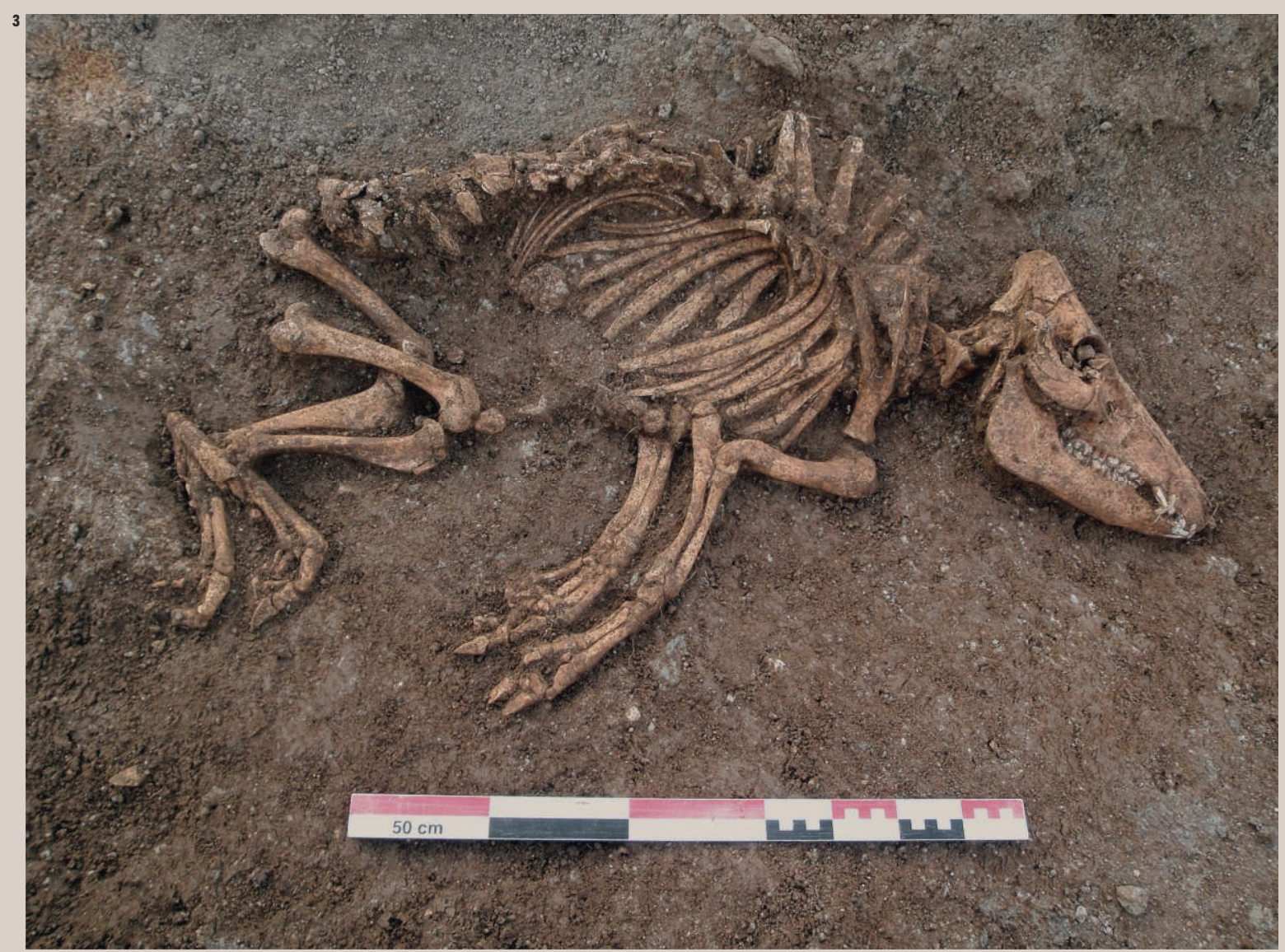

où les truies ont été exhumées dans des fossés, les structures d'habitation semblent peu éloignées. Sur trois de ces sites, la part du porc en nombre de restes est comprise entre le tiers et la moitié des effectifs de la triade (porc, bœuf, mouton/chèvre) : $31 \%$ à Neuville-auxBois (nombres de restes triade : 251), 45,4\% à Prasville (nombre des restes triade : 750) et environ $50 \%$ à Allonnes (nombre de restes triade : 1951). Ces proportions se rencontrent fréquemment sur la plupart des sites gaulois au nord de la Gaule et confirment la place importante du porc dans la consommation carnée de ces sociétés (IMéniel et al., 2009).

Ces découvertes de truies sont inédites en Gaule et viennent nourrir les réflexions sur le statut du porc dans les sociétés gauloises. Tout d'abord, on observe une discordance entre les fortes usures dentaires, indice d'un âge plutôt élevé de l'animal, et l'épiphysation incomplète des os de quelques squelettes, qui indique que les individus ont moins de sept ans, âge au-delà duquel tous les os devraient être épiphysés (Barone, 1986). Ceci peut avoir plusieurs origines, carence alimentaire ou maladies, entre autres, et constituer des indices indirects sur la qualité de l'entretien du cheptel porcin. Fnfin, dans les trois cas déjà étudiés, l'animal ne porte pas de traces de mise à mort (mais l'égorgement peut ne pas laisser de trace), ni de prélèvement, de viande. Les truies ayant été déposées couchées sur un flanc, cela écarte l'hypothèse d'un rejet désordonné. Ce « soin » apporté à ces femelles mortes pourrait être lié à l'image symbolique forte - l'espèce est notamment particulièrement féconde - qu'ont eu les suidés dans les sociétés pré et protohistoriques. Ces vieilles truies vivant dans les exploitations agricoles gauloises auraient-elles été l'objet d'une attention privilégiée, une attention proche de celle portée à leurs congénères dans les sociétés ǵréco-romaines (Pastoureau, 2009)?
Références bibliographiques

BAIlleUX G. ET VACASSI G., 2011, Fouille de trois habitat protohistoriques et antiques : Lot 1, Allonnes, La Petite Contrée (secteur 3 et 4), L'Ouche Pigeonnier (secteur 5 ) rapport de fouille d'archéologie préventive, Orléans, Inrap, SRA Centre, 5 vol.

BARONe R., 1986, Anatomie comparée des mammifères domestiques. Tome 1: ostéologie, Paris, éditions Vigot frères, $3^{\mathrm{e}}$ édition, $761 \mathrm{p}$.

HorARD-Herbin M.-P., 1997, Le Village celtique des Arènes à Levroux. L'élevage et les productions animales dans l'économie de la fin du second âge du Fer, Tours, Revue archéologique du Centre de la France, $12^{\mathrm{e}}$ supplément, $206 \mathrm{p}$

Josset D., 2009, Commune de Neuville-aux-Bois (Loiret), La Grande Route : Site A19 - C1, Région Centre Département du Loiret, rapport de fouille d'archéologie préventive, Orléans, Inrap, SRA Centre, $593 \mathrm{p}$.

Lusson D., 2011, Occupations du IV et du début du III ${ }^{e}$ s. avant notre ère: Eure-et-Loir, Prasville, «Les Gandes Canettes » (site 35), rapport de fouille d'archéologie préventive, Orléans, Inrap, SRA Centre, 262 p.

MÉnIEL P., 2001, Les Gaulois et les Animaux, élevage, repas et sacrifice, Paris, éditions Errance, $127 \mathrm{p}$

MÉNIEL P., 2005, « Porc et sanglier en Gaule septentrionale, entre archéozoologie et imaginaire collectif », Munibe, $\mathrm{n}^{\circ} 57$, p. 5-10.

Méniel P., Auxiette G., Germinet D., Baudry A., Horard-Herbin M.-P., 2009, « Une base de données sur les études de faunes des établissements ruraux en Gaule », in Bertrand I., Duval A., Gomez De Soto J. ET MAGUER P. (DIR.), Habitats et paysages ruraux en Gaule et regards sur d'autres régions du monde celtique, actes du XXXIe colloque international de l'AFEAF, mai 2007, Chauvigny, tome II, p. 417-446.

Pastoureau M., 2009, Le Cochon - Histoire d'un cousin mal aimé, Paris, éditions Gallimard, 159 p. 